\title{
Formononetin ameliorates high glucose-induced endothelial dysfunction by inhibiting the JAK/STAT signaling pathway
}

\author{
ZHEN ZHOU $^{1}$, XINJIAN ZHOU ${ }^{2}$, YOUHONG DONG ${ }^{3},{\text { MINGYI } \mathrm{LI}^{2} \text { and YANCHENG XU }}^{1}$ \\ ${ }^{1}$ Department of Endocrinology, Zhongnan Hospital of Wuhan University, Wuhan, Hubei 430071; \\ Departments of ${ }^{2}$ Endocrinology and ${ }^{3}$ Oncology, Xiangyang First People's Hospital Affiliated to \\ Hubei University of Medicine, Xiangyang, Hubei 441000, P.R. China
}

Received July 19, 2018; Accepted May 9, 2019

DOI: $10.3892 / \mathrm{mmr} .2019 .10512$

\begin{abstract}
High glucose-induced endothelial Janus kinase (JAK)/signal transducer and activator of transcription (STAT) signaling is associated with the development and progression of the vascular complications of diabetes. The present study aimed to investigate whether formononetin, a biologically active compound isolated from Astragalus membranaceus (Fisch.) Bge, was able to regulate the JAK/STAT signaling pathway, improving endothelial function. In the present study, formononetin was identified to act as a JAK2 inhibitor, similarly to tyrphostin AG 490 (AG490), by significantly inhibiting the phosphorylation and the mRNA expression levels of JAK2 and STAT in HUVECs exposed to high glucose levels. In addition, formononetin and AG490 improved the viability of HUVECs and inhibited the protein expression levels of caspase-3. Furthermore, formononetin and AG490 attenuated the inflammatory response in HUVECs by downregulating the protein and mRNA expression levels of interleukin (IL)-1 $\beta$ and intercellular adhesion molecule 1 (ICAM-1). Formononetin and AG490 also restored nitric oxide (NO) synthesis in HUVECs. Notably, formononetin was able to reverse the abnormal levels of phosphorylated (p)-JAK2, p-STAT3, IL-1 $\beta$, ICAM-1 and NO induced by cotreatment with high glucose and IL-6, an agonist of the JAK/STAT signaling pathway. Additionally, the present results suggested that formononetin restored phenylephrine-mediated contraction and acetylcholine-induced relaxation in aortic tissues of rats fed a high-glucose diet, in a dose-dependent manner. Collectively, formononetin could improve endothelial function under glucose stress in vivo and in vitro, suggesting that formononetin may represent a novel potential therapeutic compound to treat diabetic vascular complications.
\end{abstract}

Correspondence to: Professor Yancheng $\mathrm{Xu}$, Department of Endocrinology, Zhongnan Hospital of Wuhan University, 169 Donghu Road, Wuhan, Hubei 430071, P.R. China

E-mail: xuyancheng2000@sina.com

Key words: formononetin, endothelial dysfunction, Janus kinase, signal transducer and activator of transcription, diabetes

\section{Introduction}

In total, 415 million people suffer from type 2 diabetes mellitus (T2DM) worldwide, and $2 / 3$ of cases of diabetes-associated mortality are caused by cardiovascular complications $(1,2)$. T2DM was the sixth major cause of disability in 2015, and has caused a significant economic burden on society and individuals, with an estimated total cost of $\sim 825$ billion dollars (2). High glucose-induced endothelial dysfunction is associated with the development and progression of diabetic vascular complications, including atherosclerosis and heart failure (3-5). High glucose levels activate the nuclear factor- $\kappa \mathrm{B}$ and the $\mathrm{p} 38$ mitogen-activated protein kinase signaling pathways, leading to endothelial damage (6-9). Therefore, the development of novel strategies to control the effects of high glucose levels is necessary to prevent the complications of diabetes (10).

The Janus kinase (JAK)/signal transducer and activator of transcription (STAT) signaling pathway is a multifunctional mediator involved in the signal transduction from extracellular molecules to the nucleus, regulating gene expression $(11,12)$. The binding of extracellular molecules, including cytokines and growth factors, to their corresponding receptors induces dimerization of the receptors, which allows JAKs associated with the receptors to interact, inducing the phosphorylation of conserved tyrosines and activation of the downstream signal. The phosphorylated tyrosine residues and the surrounding amino acids form a docking site. Subsequently, the SH2 domain of STAT protein interacts with this docking site and JAK catalyzes the phosphorylation of the STAT protein bound to the receptor. Finally, the activated STAT protein enters the nucleus as a dimer and binds to the promoters of its target genes, regulating gene expression (11). Manea et al (13) identified that the JAK/STAT signaling pathway serves a role in the impairment of endothelial function under high glucose conditions. In addition, Marrero et al (14) suggested that inhibition of the JAK/STAT signaling pathway significantly ameliorates diabetic nephropathy. Therefore, it is important to develop novel drugs with limited side effects able to regulate the JAK/STAT signaling pathway, in order to prevent diabetic complications.

Formononetin is the main active component found in the root of Astragalus membranaceus (Fisch.) Bge, which has been used as a herbal medicine to treat diabetes in traditional 
Chinese medicine $(15,16)$. Formononetin has been shown to be effective in protecting diabetic endothelium (17-19); however, whether formononetin is able to improve endothelial function by regulating the JAK/STAT signaling pathway remains unclear. Therefore, the present study aimed to investigate this hypothesis, which may provide a scientific basis for the development of novel therapeutic strategies based on this natural medicine for the prevention and treatment of diabetic vascular complications.

\section{Materials and methods}

Materials. HUVECs were purchased from the American Type Culture Collection. Formononetin (purity, 98\%) was purchased from Gracia Chemicals Pvt. Ltd. Tyrphostin AG 490 (AG490; a JAK2 inhibitor) was purchased from MedChemExpress LLC. Recombinant human interleukin (IL)-6 was purchased from Sigma-Aldrich (Merck KGaA). Anti-phosphorylated (p)-JAK2 (cat. no. ab32101), anti-JAK2 (cat. no. ab39636), anti-p-STAT3 (cat. no. ab76315), anti-STAT3 (cat. no. ab68153), anti-cleaved caspased-3 (cat. no. ab49822), anti-GAPDH (cat. no. ab70699) and a secondary horseradish peroxidase-conjugated goat anti-rabbit antibody (cat. no. ab7090) were purchased from Abcam. IL-1 $\beta$ (cat. no. JLC6382) and intercellular adhesion molecule 1 (ICAM-1) ELISA kit (cat. no. JLC5547-96T) were purchased from Shanghai Jingkang Biological Engineering Co., Ltd. PCR materials and kits, including Transzol Up kit, TransScript II First-Strand cDNA Synthesis SuperMix kit and TransStart Top Green qPCR Super Mix kit, were purchased from Beijing Transgen Biotech Co., Ltd. MTT, 3-amino, 4-aminomethyl-2',7'-difluorescein diacetate (DAF-FM DA) and a cell lysis buffer kit were obtained from Beyotime Institute of Biotechnology.

Cell culture. HUVECs were cultured in Dulbecco's modified Eagle's medium (DMEM; Gibco; Thermo Fisher Scientific, Ltd.) supplemented with $5.5 \mathrm{mM}$ glucose and $10 \%$ fetal bovine serum (Zhejiang Tianhang Biotechnology Co., Ltd.), $100 \mathrm{U} / \mathrm{ml}$ penicillin and $100 \mathrm{U} / \mathrm{ml}$ streptomycin. Cells were cultured at $37^{\circ} \mathrm{C}$ in an atmosphere containing $5 \% \mathrm{CO}_{2}$ and $95 \%$ humidity. Medium was replaced with fresh DMEM every day. Cells were passaged at $80 \%$ confluence.

Western blotting. HUVECs were seeded in 6-well-plates $\left(6 \times 10^{4}\right.$ cells/well) and treated with glucose $(5$ and $25 \mathrm{mM})$, IL-6 (10 ng/ml), formononetin (2, 20 and $200 \mu \mathrm{M})$ and AG490 $(80 \mu \mathrm{M})$ in combination for $24 \mathrm{~h}$ at $36^{\circ} \mathrm{C}$. Total cellular protein was extracted using a protein extraction kit (Beyotime Institute of Biotechnology) according to the manufacturer's protocol. Total protein was quantified using a bicinchoninic protein assay kit. Subsequently, $25 \mu \mathrm{g}$ protein was loaded into each lane and proteins were separated by $10 \%$ SDS-PAGE and transferred onto polyvinylidene fluoride (PVDF) membranes (EMD Millipore). PVDF membranes were blocked using TBS containing 5\% skimmed milk and $0.05 \%$ Tween 20 at $37^{\circ} \mathrm{C}$ for $3 \mathrm{~h}$, followed by incubation with the primary antibody (1:300 dilution) at $4^{\circ} \mathrm{C}$ for $10 \mathrm{~h}$ and with secondary antibodies $(1: 1,000$ dilution $)$ at $37^{\circ} \mathrm{C}$ for $2.5 \mathrm{~h}$. Protein bands were detected using BeyoECL Moon (Beyotime Institute of Biotechnology) and a ChemiDoc XRS system (Bio-Rad Laboratories, Inc.) and analyzed using ImageJ software (1.8.0; National Institutes of Health).
$R N A$ analysis by reverse transcription-quantitative (q)PCR. HUVECs were seeded in 6-well-plates $\left(6 \times 10^{4}\right.$ cells/well) and treated with glucose (5 and $25 \mathrm{mM})$, IL-6 (10 ng/ml), formononetin $(2,20$ and $200 \mu \mathrm{M})$ or AG490 $(80 \mu \mathrm{M})$ in combination for $24 \mathrm{~h}$ at $36^{\circ} \mathrm{C}$. Subsequently, total RNA was extracted with the Transzol Up kit (Beijing Transgen Biotech Co., Ltd.), according to the manufacturer's protocol. A total of $5 \mu \mathrm{g}$ RNA from each experimental group was used to synthesize the cDNA, according to manufacturer's protocol. Gene expression was determined using the TransStart Top SYBR Green qPCR Super Mix kit and analyzed using CFX manager 2.1 (Bio-Rad Laboratories, Inc.). The thermocycling conditions were as follows: Initial denaturation at $93^{\circ} \mathrm{C}$ for $4 \mathrm{~min}$, followed by 33 cycles at $93^{\circ} \mathrm{C}$ for $16 \mathrm{sec}$ and $60^{\circ} \mathrm{C}$ for $35 \mathrm{sec}$. The primer sequences were as follows: JAK2, forward, (F) 5'-TCTGGGGAGTATGTTGCAGAA-3', reverse (R) 5'-AGACATGGTTGGGTGGATACC-3'; STAT3, F 5'-CAG CAGCTTGACACACGGTA-3', R 5'-AAACACCAAAGTGGC ATGTGA-3'; IL-1 $\beta$, F 5'-AGCTACGAATCTCCGACCAC-3', R 5'-CGTTATCCCATGTGTCGAAGAA-3'; ICAM-1, F 5'-ATG CCCAGACATCTGTGTCC-3', R 5'-GGGGTCTCTATGCCC AACAA-3'; and $\beta$-actin, F 5'-CCTTATTCCGATCTACACAGA GC-3' and R 5'-TATTCGGCGTAGGTCTGAGGG-3'. $\beta$-actin was used as the internal control (20).

Cell viability assay. To detect the effect of formononetin on cellular viability, an MTT assay was performed. HUVECs were seeded in a 96-well plate $\left(1 \times 10^{4}\right.$ cells/well $)$ and were treated with glucose (5 and $25 \mathrm{mM})$, formononetin $(2,20$ and $200 \mu \mathrm{M}), \mathrm{AG} 490(80 \mu \mathrm{M})$ and mannitol $(25 \mathrm{mM})$ in combination for $24 \mathrm{~h}$ at $36^{\circ} \mathrm{C}$. After $24 \mathrm{~h}$ treatment, $20 \mu \mathrm{l} \mathrm{MTT}$ solution $(5 \mathrm{mg} / \mathrm{ml})$ was added into each well for $4 \mathrm{~h}$ at $36^{\circ} \mathrm{C}$. DMSO (150 $\mu \mathrm{l} /$ well) was used to dissolve the formazan crystals. Cell viability was measured using a scanning multiwell spectrophotometer at a wavelength of $570 \mathrm{~nm}$.

$I L-1 \beta$ and ICAM-1 measurement by ELISA. HUVECs were seeded in 6-well-plates $\left(6 \times 10^{4}\right.$ cells/well) and treated with glucose (5 and $25 \mathrm{mM})$, formononetin $(2,20$ and $200 \mu \mathrm{M})$ and AG490 $(80 \mu \mathrm{M})$ in combination for $24 \mathrm{~h}$ at $36^{\circ} \mathrm{C}$. Subsequently, IL-1 $\beta$ and ICAM-1 protein concentrations in the cell supernatants were analyzed using ELISA kits, according to the manufacturer's protocol.

Intracellular nitric oxide (NO) measurement by fluorescence microscopy. HUVECs were seeded into 6-well-plates $\left(6 \times 10^{4}\right.$ cells/well $)$ and treated with glucose $(5$ and $25 \mathrm{mM})$, formononetin $(2,20$ and $200 \mu \mathrm{M})$ and AG490 $(80 \mu \mathrm{M})$ in combination for $24 \mathrm{~h}$ at $36^{\circ} \mathrm{C}$. Subsequently, cells were washed twice with PBS and incubated with $5 \mu \mathrm{M}$ DAF-FM DA (NO synthase assay kit; Beyotime Institute for Biotechnology) at $37^{\circ} \mathrm{C}$ for $25 \mathrm{~min}$. After washing with buffer solution to remove the probe, NO was detected using an Olympus fluorescence microscope (IX51S8F-3; Olympus Corporation) at an excitation wavelength of $495 \mathrm{~nm}$ and an emission wavelength of $515 \mathrm{~nm}$. ImageJ software (1.8.0; National Institutes of Health) was used to analyze fluorescence intensity.

Vascular contraction and relaxation assay. 60 Male Sprague-Dawley rats (weight, 180-200 g) were purchased from The Animal Experiment Center of Wuhan University and were 
A

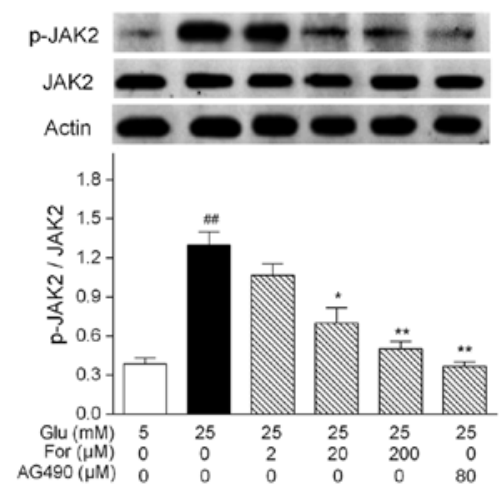

C

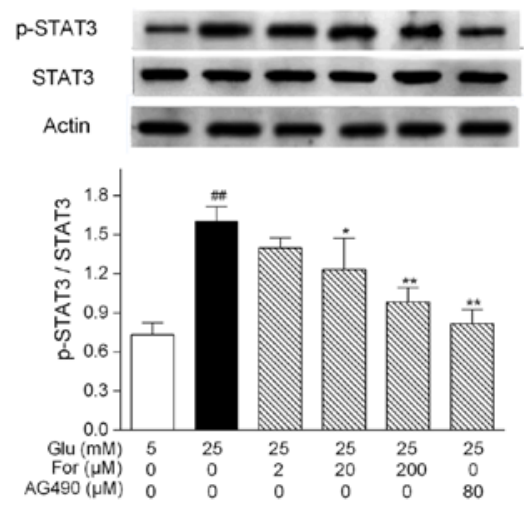

B

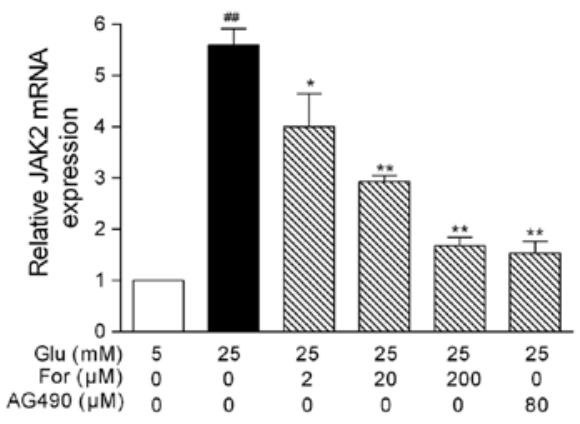

D

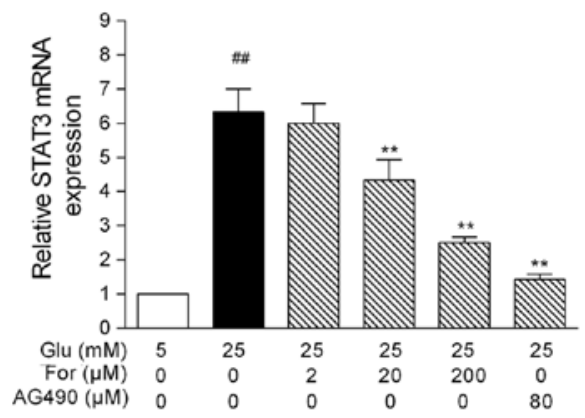

Figure 1. Effects of formononetin on JAK2 and STAT3 expression under high glucose conditions. HUVECs were treated with formononetin or AG490 under high glucose conditions. Protein expression levels of (A) JAK2 and p-JAK2, and (C) STAT3 and p-STAT3, were determined by western blot analysis. Protein bands were analyzed by densitometry. mRNA expression levels of (B) JAK2 and (D) STAT3, as determined by quantitative PCR. Results are presented as the mean \pm SEM from three independent experiments. The ratio of p-protein to total/unmodified protein was normalized to actin. ${ }^{\# \#} \mathrm{P}<0.01 \mathrm{vs}$. $5 \mathrm{mM}$ glucose group; ${ }^{*} \mathrm{P}<0.05,{ }^{* *} \mathrm{P}<0.01$ vs. $25 \mathrm{mM}$ glucose group. AG490, tyrphostin AG 490; For, formononetin; Glu, glucose; JAK2, Janus kinase 2; p-, phosphorylated; STAT3, signal transducer and activator of transcription 3 .

housed according to the institutional guidelines (temperature, $25^{\circ} \mathrm{C}$; relative humidity, 50\%-60; light/dark cycle, $12 \mathrm{~h}$ ) with free access to food and water. All experimental procedures and protocols were approved by The Institutional Animal Care and Use Committee of the Institute for Endocrinology, Xiangyang First People's Hospital. After acclimation for 10 days, rats were divided into six groups ( $\mathrm{n}=10 /$ group): i) Control group; ii) high glucose group; iii) $4 \mathrm{mg} / \mathrm{kg}$ formononetin group; iv) $40 \mathrm{mg} / \mathrm{kg}$ formononetin group; v) $400 \mathrm{mg} / \mathrm{kg}$ formononetin group; and vi) $8 \mathrm{mg} / \mathrm{kg}$ AG490 group. Drugs were delivered through intragastric administration every day. Untreated rats in the control group were fed a standard diet (NIH-41). The other five groups were fed a high glucose diet [10\% lard oil, $20 \%$ sucrose, $2.5 \%$ egg yolk powder, $0.5 \%$ cholesterol, $0.5 \%$ sodium cholate and $66.5 \%$ standard diet $(\mathrm{w} / \mathrm{w})]$. The rats were sacrificed after 12 weeks of treatment. Thoracic aortas form the rats were dissected to examine thoracic aortic function. For the thoracic aortic function analysis, isolated thoracic aortas in each group were treated with chilled Krebs-Henseleit (K-H) solution ( $\mathrm{pH}$ 7.4). The composition of the solution was as follows: $117.9 \mathrm{mM} \mathrm{NaCl}, 4.7 \mathrm{mM} \mathrm{KCl}, 2.6 \mathrm{mM} \mathrm{MgCl}_{2}, 3.3 \mathrm{mM} \mathrm{CaCl}_{2}$, $25.0 \mathrm{mM} \mathrm{NaHCO}, 1.2 \mathrm{mM} \mathrm{KH}_{2} \mathrm{PO}_{4}$ and $11.0 \mathrm{mM}$ glucose. Aortas were isolated, and after removing tissue debris, aortic rings (length, 4-7 $\mathrm{mm}$ ) were separated from the aortas. The aortic rings were equilibrated for $1 \mathrm{~h}$ at $37^{\circ} \mathrm{C}$ with a resting tension of $1.5 \mathrm{~g}$. Subsequently, the aortic rings were incubated with high $\mathrm{K}^{+}(60 \mathrm{mM})$ solution for $20 \mathrm{~min}$ at $37^{\circ} \mathrm{C}$ to induce maximal contraction. Then, vascular contraction induced by phenylephrine $\left(10^{-9}, 10^{-8}, 10^{-7}\right.$ and $10^{-6} \mathrm{~mol} / \mathrm{l}$; Sigma-Aldrich; Merck $\mathrm{KGaA}$ ) for $20 \mathrm{~min}$ at $37^{\circ} \mathrm{C}$ was recorded using a force-displacement transducer connected to a polygraph. Phenylephrine was added cumulatively until the maximum response was detected. A cumulative dose-response curve was calculated, and, after addition of phenylephrine, the maximum response was determined when the dose-response curve reached a plateau. Contraction responses were calculated using the following formula: Contraction response $=[$ contraction tension-resting tension)/resting tension] x $100 \%$. Before determining the degree of relaxation, the aortic rings were washed three times with $\mathrm{K}-\mathrm{H}$ solution every $20 \mathrm{~min}$ and recontraction was induced with $10^{-6} \mathrm{~mol} / \mathrm{l}$ phenylephrine. The cumulative dose-response curves for acetylcholine $\left(10^{-9}, 10^{-8}, 10^{-7}, 10^{-6}\right.$ and $10^{-5} \mathrm{~mol} / \mathrm{l}$; Sigma-Aldrich; Merck KGaA) for $20 \mathrm{~min}$ at $37^{\circ} \mathrm{C}$ were calculated to evaluate endothelial relaxation. Relaxant response was calculated as the percentage decrease of the contraction amplitude induced by phenylephrine before the application of acetylcholine.

Statistical analysis. SPSS version 24.0 (IBM Corp.) was used for statistical analysis. The Shapiro-Wilk normality test was performed, and all variables were found to be normally distributed. Data are presented as the mean \pm SEM from 
A
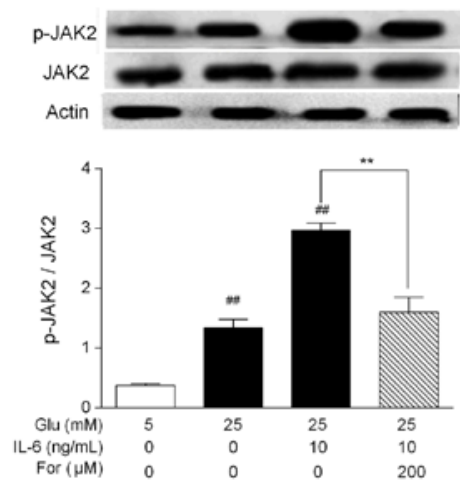

C

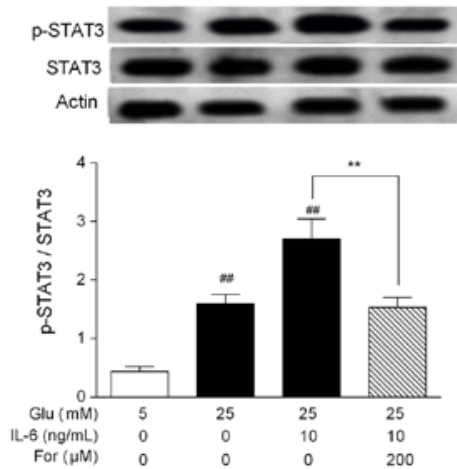

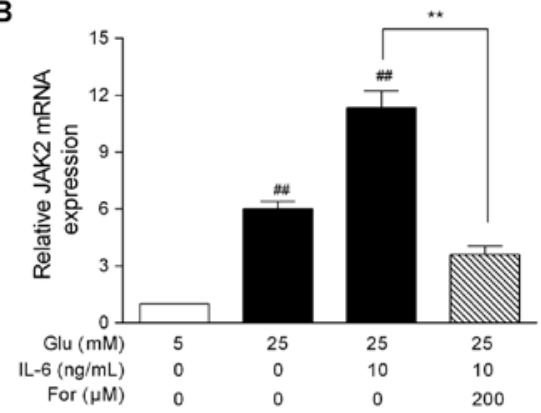

D

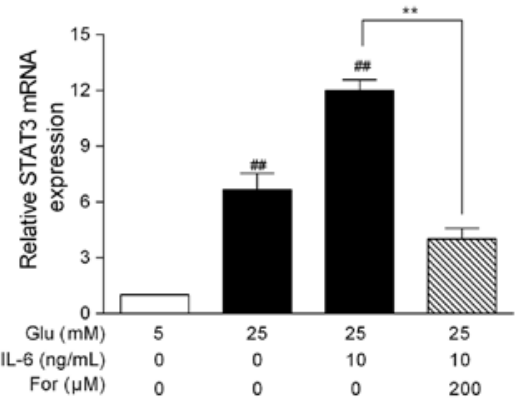

Figure 2. Effects of formononetin on JAK2 and STAT3 expression under high glucose conditions and following IL-6 treatment. HUVECs were cotreated with glucose + IL-6 and were treated with formononetin. Protein expression levels of (A) JAK2 and p-JAK2, and (C) STAT3 and p-STAT3, were determined by western blotting. Protein bands were analyzed by densitometry. mRNA expression level of (B) JAK2 and (D) STAT3, as determined by quantitative PCR. Results are presented as the mean \pm SEM from three independent experiments. ${ }^{\# \#} \mathrm{P}<0.01$ vs. $5 \mathrm{mM}$ glucose group; ${ }^{* *} \mathrm{P}<0.01$, as indicated. AG490, tyrphostin AG 490; For, formononetin; Glu, glucose; IL-6, interleukin-6; JAK2, Janus kinase 2; p-, phosphorylated; STAT3, signal transducer and activator of transcription 3 .

A

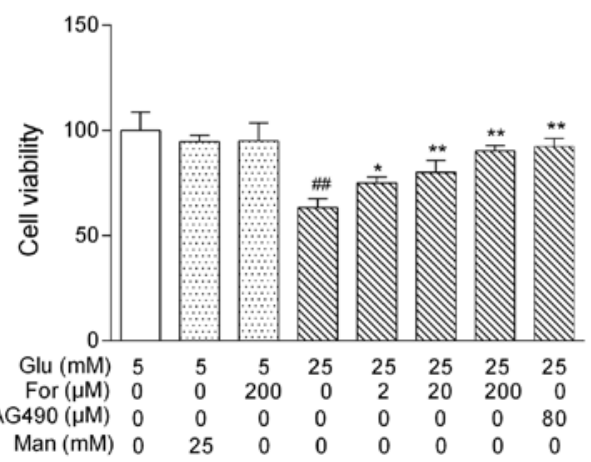

C

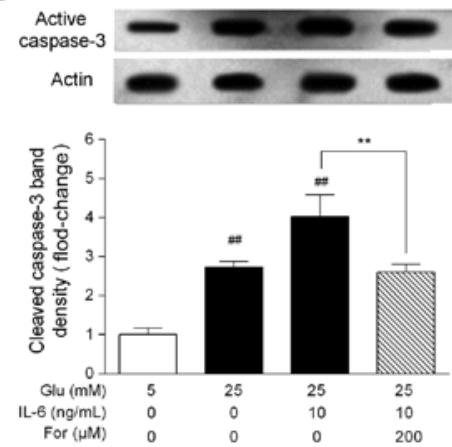

B
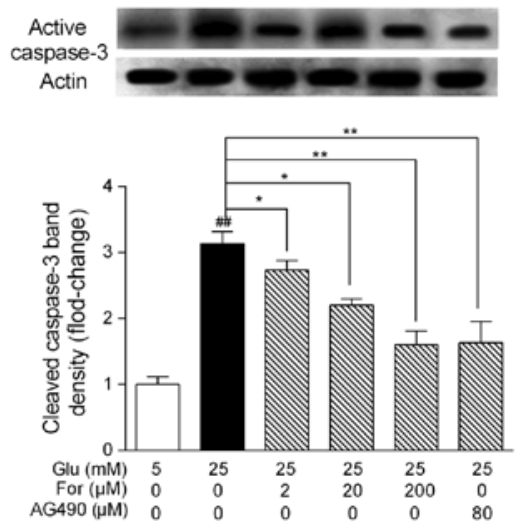

Figure 3. Effects of formononetin on cell viability and apoptosis. HUVECs were treated with glucose or were cotreated with glucose + IL-6, and were treated with formononetin or AG490. (A) MTT assay was performed to assess cellular viability. (B) Protein expression levels of active caspase-3 were determined by western blotting. (C) Protein expression levels of active caspase-3 following treatment with IL-6. Protein bands were analyzed by densitometry. Results are presented as the mean \pm SEM from three independent experiments. ${ }^{\sharp \# / P}<0.01$ vs. $5 \mathrm{mM}$ glucose group. ${ }^{*} \mathrm{P}<0.05,{ }^{* *} \mathrm{P}<0.01$, as indicated. AG490, tyrphostin AG 490; For, formononetin; Glu, glucose; IL-6, interleukin-6; Man, mannitol. 

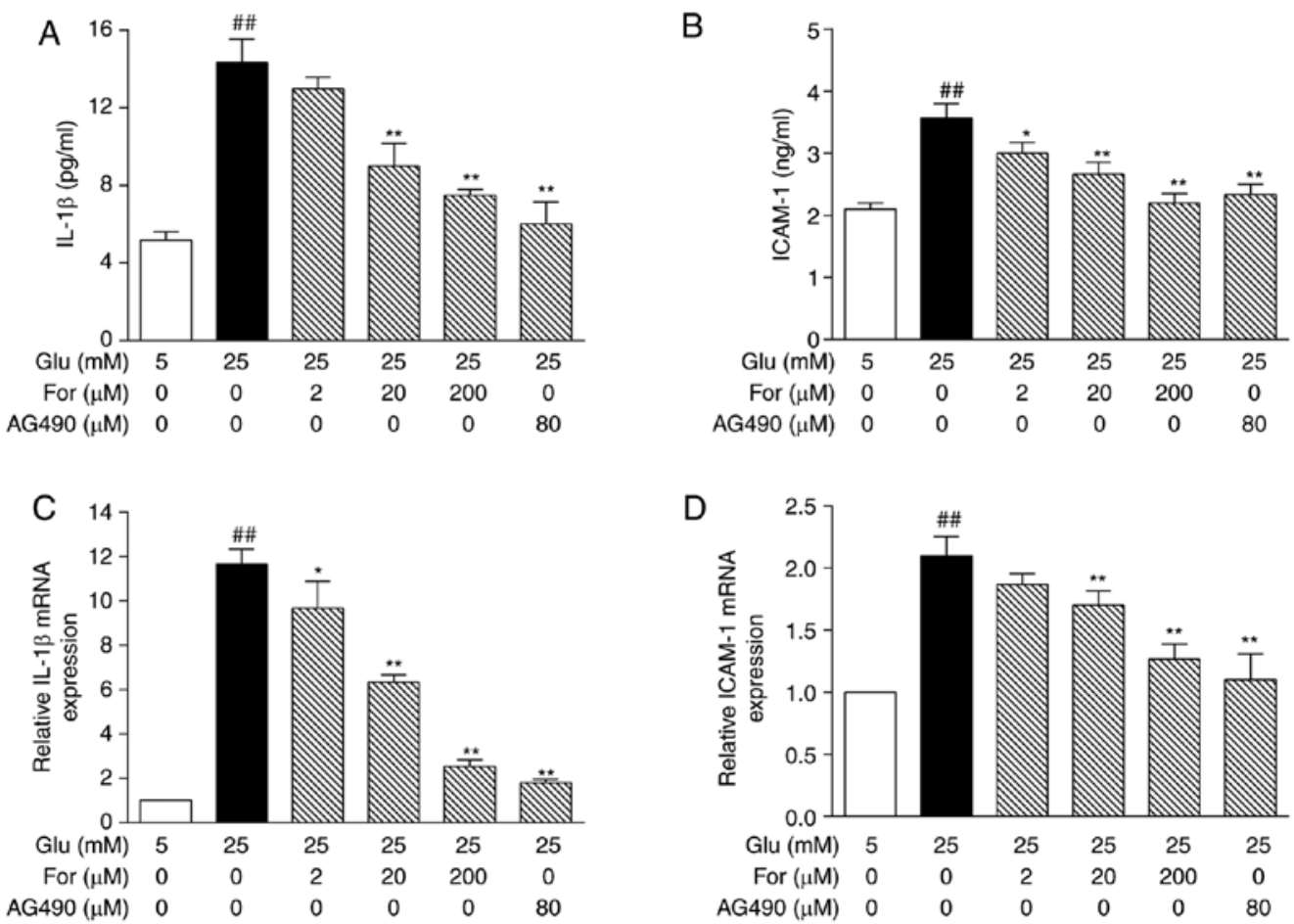

Figure 4. Effects of formononetin on IL-1 $\beta$ and ICAM-1 expression under high glucose conditions. HUVECs were treated with formononetin or AG490 under high glucose conditions. (A) IL-1 $\beta$ and (B) ICAM-1 protein levels in the supernatants of HUVECs were determined by ELISA. (C) IL-1 $\beta$ and (D) ICAM-1 mRNA expression levels were determined by quantitative PCR. ${ }^{\# \#} \mathrm{P}<0.01$ vs. $5 \mathrm{mM}$ glucose group, ${ }^{*} \mathrm{P}<0.05,{ }^{* *} \mathrm{P}<0.01$ vs. $25 \mathrm{mM}$ glucose group. AG490, tyrphostin AG 490; For, formononetin; Glu, glucose; ICAM-1, intercellular adhesion molecule 1; IL, interleukin.
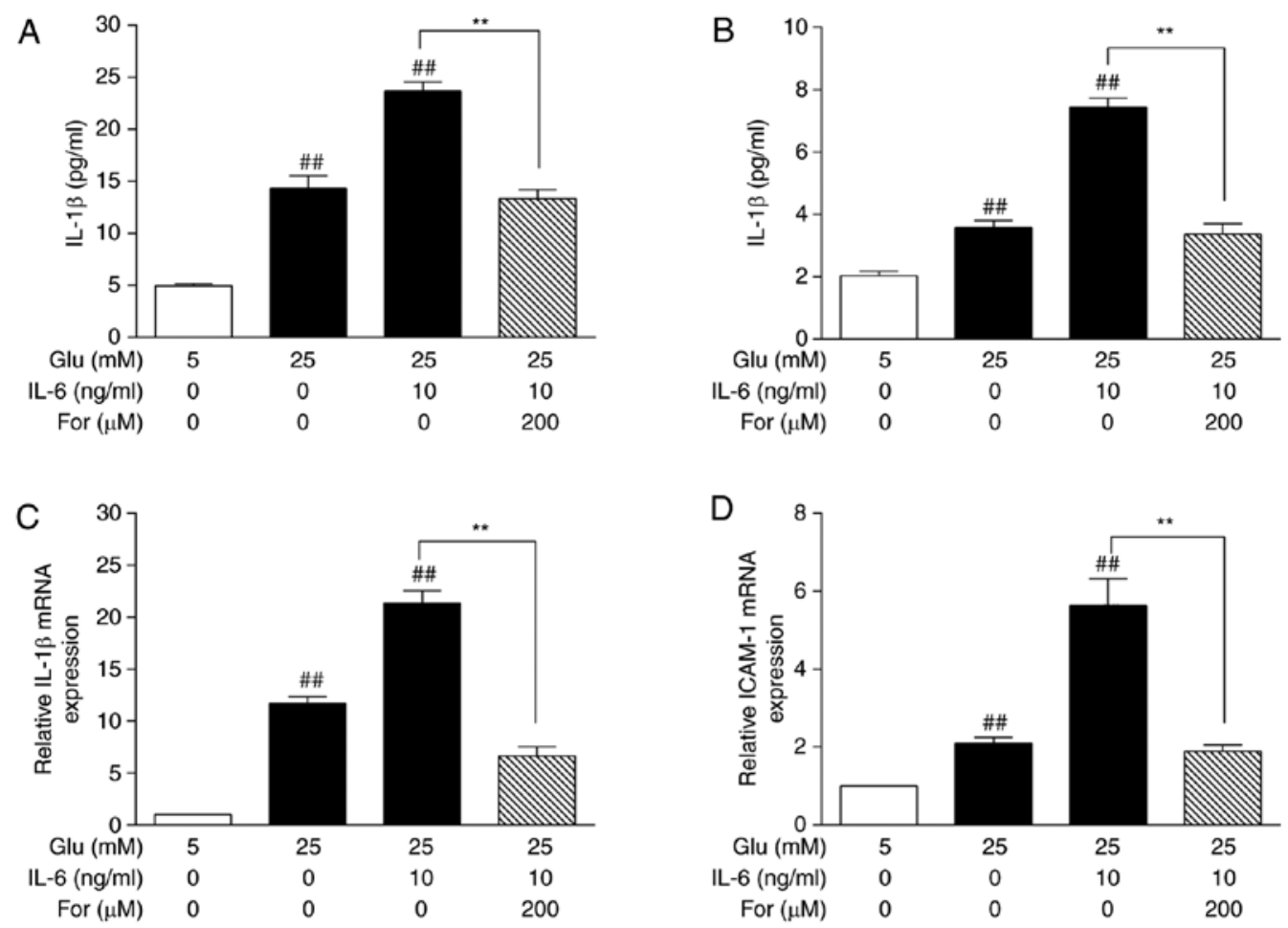

Figure 5. Effects of formononetin on IL-1 $\beta$ and ICAM-1 expression under high glucose and following IL-6 treatment. HUVECs were cotreated with glucose + IL-6 and were treated with formononetin. (A) IL-1 $\beta$ and (B) ICAM-1 protein levels in the supernatants of HUVECs were determined by ELISA. (C) IL-1 $\beta$ and (D) ICAM-1 mRNA expression levels were determined by quantitative PCR. ${ }^{\# \#} \mathrm{P}<0.01$ vs. 5 mM glucose group; ${ }^{* *} \mathrm{P}<0.01$, as indicated. For, formononetin; Glu, glucose; ICAM-1, intercellular adhesion molecule 1; IL, interleukin.

three experiments. One-way analysis of variance followed by Tukey's test was used to compare multiple groups.
$\mathrm{P}<0.05$ was considered to indicate a statistically significant difference. 
A

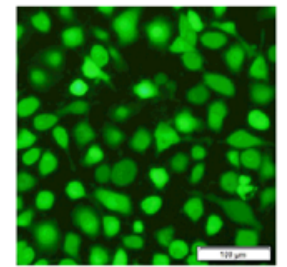

$5 \mathrm{mM}$ Glu

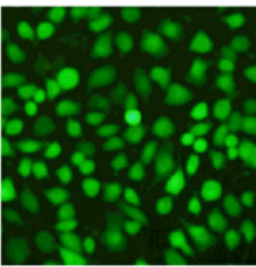

$25 \mathrm{mM}$ Glu $20 \mu \mathrm{M}$ For

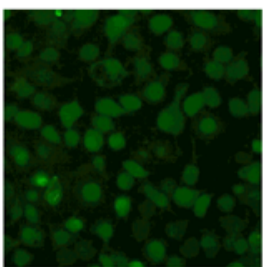

25 mM Glu

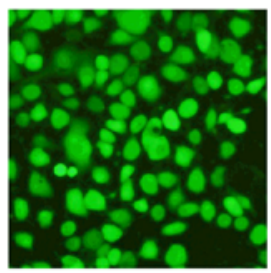

$25 \mathrm{mM}$ Glu

$200 \mu \mathrm{M}$ For

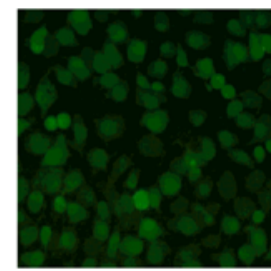

25 mM Glu+10 ng/ml IL-6

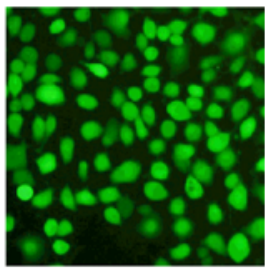

$25 \mathrm{mM}$ Glu

$80 \mu \mathrm{M}$ AG490

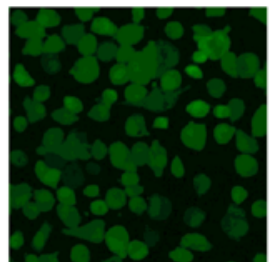

$25 \mathrm{mM}$ Glu

$2 \mu \mathrm{M}$ For

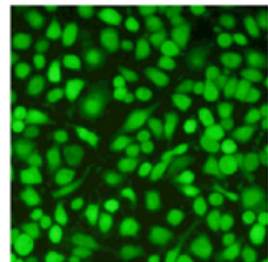

$25 \mathrm{mM}$ Glu+10 ng/ml IL-6 $200 \mu \mathrm{M}$ For

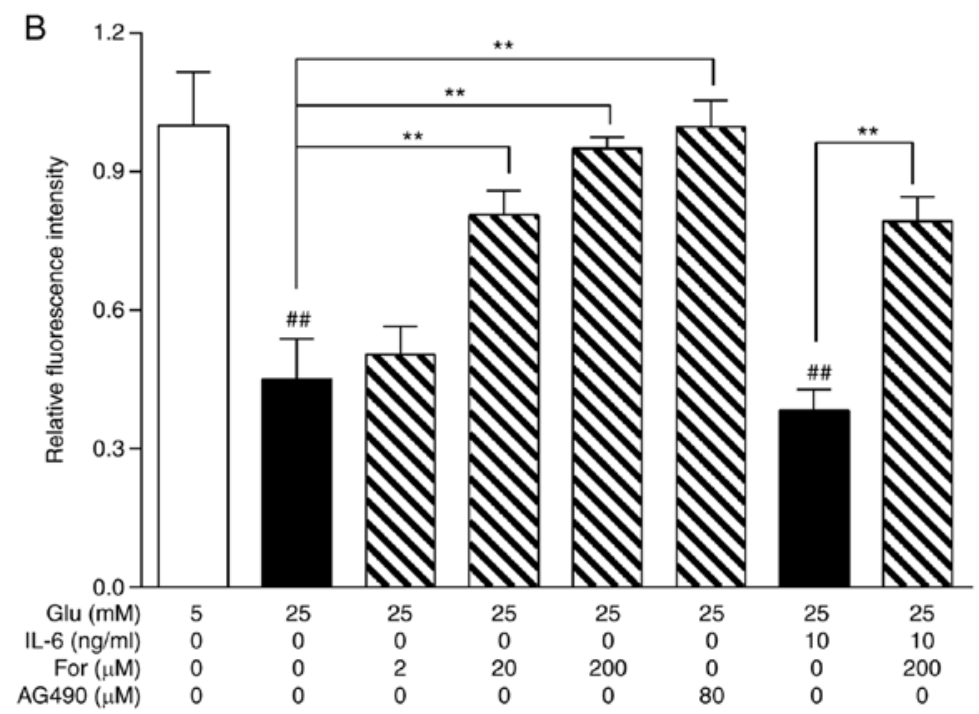

Figure 6. Effects of formononetin on NO production. HUVECs were treated with glucose or were cotreated with glucose + IL-6, and were treated with formononetin or AG490. (A) Intracellular NO levels were visualized using fluorescence microscopy (scale bar, $100 \mu \mathrm{m}$ ). (B) Quantification of NO-associated florescence intensity was analyzed with ImageJ. Results are presented as the mean \pm SEM from three independent experiments. ${ }^{\# \#} \mathrm{P}<0.01$ vs. 5 mM glucose group; ${ }^{* *} \mathrm{P}<0.01$, as indicated. AG490, tyrphostin AG 490; For, formononetin; Glu, glucose; ICAM-1, intercellular adhesion molecule 1; IL-6, interleukin-6; NO, nitric oxide.
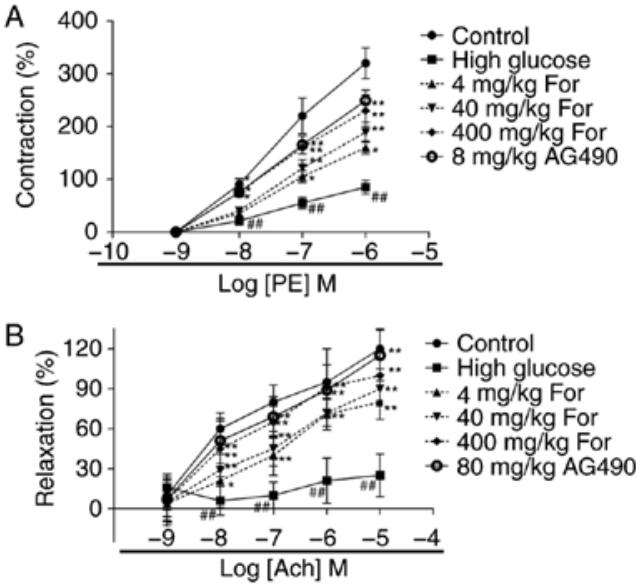

Figure 7. Effects of formononetin on thoracic aortic function. Cumulative dose-response curves of (A) PE-induced contraction and (B) Ach-induced relaxation were measured by rat aortic ring assays. ${ }^{\# \prime} \mathrm{P}<0.01$ vs. control group; ${ }^{*} \mathrm{P}<0.05,{ }^{* *} \mathrm{P}<0.01$ vs. high glucose group. Ach, acetylcholine; AG490, tyrphostin AG 490; For, formononetin; PE, phenylephrine.

\section{Results}

Effects of formononetin on the JAK/STAT signaling pathway. High glucose levels can activate the JAK/STAT signaling pathway in HUVECs (13). Therefore, the effects of formononetin on the JAK/STAT signaling pathway were investigated in HUVECs. Treatment with $25 \mathrm{mM}$ glucose for $24 \mathrm{~h}$ significantly increased the protein expression levels of p-JAK2 and $\mathrm{p}$-STAT3 in HUVECs $(\mathrm{P}<0.01$; Fig. 1A and $\mathrm{C})$. Similarly to the JAK2 inhibitor AG490, treatment with 20 and $200 \mu \mathrm{M}$ formononetin significantly decreased the protein expression levels of p-JAK 2 and JAK 2 mRNA expression ( $\mathrm{P}<0.05$; Fig. 1A and B). Furthermore, 20 and $200 \mu \mathrm{M}$ formononetin significantly inhibited the protein expression levels of p-STAT3, a protein downstream to JAK2, and STAT3 mRNA expression ( $\mathrm{P}<0.05$; Fig. $1 \mathrm{C}$ and $\mathrm{D})$. Additionally, the JAK/STAT signaling agonist IL-6 was used to examine the pharmacological effects of formononetin. Even when HUVECs were cotreated with high glucose and IL-6, formononetin was able to significantly 
inhibit p-JAK2 and p-STAT3 protein levels ( $<<0.01$; Fig. 2A and $\mathrm{C}$ ), in addition to the mRNA expression levels of JAK2 and STAT3 ( $\mathrm{P}<0.01$; Fig. 2B and D). Collectively, the present results suggested that formononetin, similarly to AG490, was able to inhibit the JAK/STAT signaling pathway in HUVECs treated with high glucose.

Effects of formononetin on high glucose-induced cellular damage. After investigating the role of formononetin in the JAK/STAT signaling pathway in HUVECs, the effects of formononetin on HUVEC viability were examined under high glucose conditions. Following high glucose stress, the viability of HUVECs was decreased to 67\% (Fig. 3A). There was no significant difference in cellular viability between the $25 \mathrm{mM}$ mannitol group and the $5 \mathrm{mM}$ glucose-control group, suggesting that the decreased viability in high glucose was not related to osmotic pressure. However, formononetin increased cellular viability under high glucose stress in a dose-dependent manner $(\mathrm{P}<0.05)$. Furthermore, formononetin could significantly decrease the protein expression levels of active caspase- 3 in HUVECs treated with high glucose or cotreated with high glucose and IL-6 $(\mathrm{P}<0.05$; Fig. $3 \mathrm{~B}$ and $\mathrm{C})$. In order to investigate the inhibitory effects of formononetin on inflammation, the expression levels of IL- $1 \beta$ and ICAM- 1 were investigated by ELISA and qPCR. The glucose-induced protein and mRNA expression levels of IL-1 $\beta$ and ICAM-1 were decreased after formononetin treatment, also in the presence of IL-6 ( $\mathrm{P}<0.05$; Figs. 4 and 5). Collectively, formononetin may protect against endothelial damage, at least in part, through the JAK/STAT signaling pathway.

Effects of formononetin on endothelial function. Endothelial function was examined to determine whether formononetin could improve endothelial function. High glucose stress decreased NO production, which is associated with endothelial dysfunction (21). In vitro, $\mathrm{NO}$ levels were significantly restored following treatment with 20 and $200 \mu \mathrm{M}$ formononetin, and $80 \mu \mathrm{M}$ AG490 under $25 \mathrm{mM}$ glucose conditions $(\mathrm{P}<0.01$; Fig. 6). Additionally, in HUVECs cotreated with $25 \mathrm{mM}$ glucose and $10 \mathrm{ng} / \mathrm{ml}$ IL-6, formononetin $(200 \mu \mathrm{M})$ still exhibited a protective role in NO production. Additionally, the contraction response to phenylephrine was investigated in thoracic aortic rings isolated from rats fed a high-glucose diet (Fig. 7). Compared with the control group (rats fed a standard diet), aortic rings isolated from rats in the high glucose group exhibited a significantly reduced maximal contractile response induced by phenylephrine and a significantly decreased maximal relaxation response induced by acetylcholine. Following formononetin administration at 4,40 and $400 \mathrm{mg} / \mathrm{kg}$, contraction and relaxation of aortic rings were significantly improved $(\mathrm{P}<0.05)$. The JAK2 inhibitor AG490 at $80 \mathrm{mg} / \mathrm{kg}$ exhibited similar effects to formononetin at $400 \mathrm{mg} / \mathrm{kg}$. Collectively, in vivo and in vitro results suggested that formononetin improved endothelial function under high glucose stress through the JAK/STAT signaling pathway.

\section{Discussion}

Overnutrition, a major topic of research in endocrinology, is responsible for inducing metabolic diseases, including T2DM (22). Insulin resistance in patients with T2DM leads to multiple cardiovascular diseases, including atherosclerosis and coronary disease, that are caused by impaired glucose and lipid metabolism $(23,24)$. Therefore, restoring and maintaining a normal extracellular environment is important to protect the cardiovascular system from complications associated with diabetes. Although drugs, such as insulin and thiazolidinediones, have been used to treat diabetes, their long-term side effects can be significant (25). Natural products have attracted the attention of various research groups due to their therapeutic potential and limited side effects (26). Formononetin has been shown to be effective in alleviating the symptoms of diabetes and related complications, such as cardiovascular and kidney diseases (27). Additionally, formononetin has been reported to be able to improve the function of pancreatic $\beta$-cells and whole-body glucose homeostasis $(28,29)$. In the present study, formononetin was revealed to protect endothelial function through the JAK/STAT signaling pathway, and the present results provided a scientific basis for the development of novel clinical strategies using formononetin to treat T2DM.

The JAK/STAT signaling cascade is one of multiple pleiotropic signaling cascades involved in signal transduction during development and homeostasis. In 2008, Vargha et al (30) reported that IL-6 promotes epithelial-to-mesenchymal transition of human peritoneal mesothelial cells possibly through the JAK2/STAT3 signaling pathway. Notably, the JAK/STAT signaling cascade is an important factor activated by hyperglycemia that may cause diabetes-associated endothelial dysfunction (13). JAK2 belongs to the family of non-receptor protein tyrosine kinases, which consists of JAK1, JAK2, JAK3 and tyrosine kinase 2 . To transduce its downstream signaling, activated JAK recruits the cytoplasmic transcription factor STAT to the receptor complex. To the best of our knowledge, seven STAT proteins have been identified (31). The JAK2/STAT3 pathway may be involved in the occurrence of endothelial dysfunction under glucose stress (32). In the present study, high glucose levels activated the JAK2/STAT3 signaling pathway. Furthermore, formononetin was able to significantly inhibit the JAK2/STAT3 signaling pathway following high glucose treatment or cotreatment with high glucose and IL-6, an antagonist of the JAK2/STAT3 signaling pathway.

After identification of the inhibitory effects of formononetin on the JAK/STAT signaling pathway, its effects on endothelial cells under high glucose stress were examined in the present study. Notably, formononetin could function similarly to AG490 in improving the viability of HUVECs under high glucose conditions. Caspase-3 is a key apoptosis-associated factor that interacts with other members of its family, such as caspase- 8 and caspase-9 (33). The present results suggested that formononetin could inhibit caspase- 3 activation following treatment with $25 \mathrm{mM}$ glucose or cotreatment with $25 \mathrm{mM}$ glucose and $10 \mathrm{ng} / \mathrm{ml}$ IL- 6 . The present results suggested that formononetin could prevent HUVECs damage and apoptosis by inhibiting the JAK/STAT signaling pathway.

Inflammation is a complex biological process activated in response to harmful stimuli, such as pathogens and metabolic dysfunction $(34,35)$. IL-1 $1 \beta$, activated by the NLR family pyrin domain containing 3 inflammasome, is a strong inflammatory mediator involved in endothelial cell damage $(36,37)$. IL-1 $\beta$ promotes inflammation and can also cause apoptosis. 
Formononetin significantly inhibited IL-1 $\beta$ expression at the protein and mRNA levels. In addition, formononetin could inhibit ICAM-1 expression, suggesting that formononetin may inhibit the adhesion of inflammatory cells under high glucose conditions (38). Inflammatory mediators are involved in the dysregulation of NO synthesis in HUVECs (39). Therefore, the effects of formononetin on NO synthesis were investigated in the present study. $\mathrm{NO}$ acts as a vasodilator and vascular homeostatic mediator in maintaining normal endothelial function (40). However, high glucose levels induce the JAK/STAT pathway and promote the activity of inflammatory mediators that can impair the synthesis and release of NO (41). The present results suggested that formononetin significantly restored NO synthesis under high glucose conditions or in cells cotreated with high glucose and IL-6, suggesting that formononetin could improve NO synthesis and release in HUVECs under high glucose conditions. In addition, the effects of formononetin on contraction and relaxation of isolated thoracic aortic rings were investigated in rats fed a high-glucose diet. The present results suggested that formononetin treatment significantly improved endothelial function in rats fed a high-glucose diet.

In conclusion, the present study suggested that formononetin could regulate the JAK/STAT signaling pathway, improving endothelial viability and function in vivo and in vitro. The present findings suggested that formononetin may potentially represent a novel candidate natural product that could be used to prevent and treat diabetic vascular complications.

\section{Acknowledgements}

Not applicable.

\section{Funding}

No funding was received.

\section{Availability of data and materials}

The datasets used and/or analyzed during the current study are available from the corresponding author on reasonable request.

\section{Authors' contributions}

YX designed the experiment, $\mathrm{ZZ}$ and $\mathrm{XZ}$ performed the experiments and wrote the paper. YD and ML analyzed the results. YX, ZZ, YD and ML revised the paper.

\section{Ethics approval and consent to participate}

All experimental procedures and protocols were approved by The Institutional Animal Care and Use Committee of the Institute for Endocrinology, Xiangyang First People's Hospital.

\section{Patient consent for publication}

Not applicable.

\section{Competing interests}

The authors declare that they have no competing interests.

\section{References}

1. Solomon CG: Reducing cardiovascular risk in type 2 diabetes. $\mathrm{N}$ Engl J Med 348: 457-459, 2003.

2. Chatterjee S, Khunti K and Davies MJ: Type 2 diabetes. Lancet 389: 2239-2251, 2017.

3. Paneni F, Beckman JA, Creager MA and Cosentino F: Diabetes and vascular disease: Pathophysiology, clinical consequences, and medical therapy: Part I. Eur Heart J 34: 2436-2443, 2013

4. Garber AJ: Diabetes and vascular disease. N Engl J Med 2: 1-5, 1990.

5. Murea M, Ma L and Freedman BI: Genetic and environmental factors associated with type 2 diabetes and diabetic vascular complications. Rev Diabet Stud 9: 6-22, 2012.

6. Martinon F, Burns K and Tschopp J: The inflammasome: A molecular platform triggering activation of inflammatory caspases and processing of proIL-beta. Mol Cell 10: 417-426, 2002.

7. Hink U, Tsilimingas N, Wendt M and Münzel DT: Mechanisms underlying endothelialdysfunction in diabetes mellitus: Therapeutic implications. Treat Endocrinol 2: 293-304, 2003.

8. Peng H, Hong S, Li P, Li J, Zhou X and Zhang L: High glucose concentration increases the MAPK and TGF-beta- 2 expression in cultured P38 human umbilical vein endothelial cells. Basic \& Clinical Medicine 27: 169-173, 2007. http://en.cnki.com.cn/ Article_en/CJFDTOTAL-JCYL200702010.htm.

9. Takaishi H, Taniguchi T, Takahashi A, Ishikawa $\mathrm{Y}$ and Yokoyama M: High glucose accelerates MCP-1 production via p38 MAPK in vascular endothelial cells. Biochem Biophys Res Commun 305: 122-128, 2003.

10. Barr EL, Zimmet PZ, Welborn TA, Jolley D, Magliano DJ, Dunstan DW, Cameron AJ, Dwyer T, Taylor HR, Tonkin AM, et al: Risk of cardiovascular and all-cause mortality in individuals with diabetes mellitus, impaired fasting glucose, and impaired glucose tolerance: The Australian Diabetes, Obesity, and Lifestyle Study (AusDiab). Circulation 116: 151-157, 2007.

11. Kisseleva T, Bhattacharya S, Braunstein J and Schindler CW: Signaling through the JAK/STAT pathway, recent advances and future challenges. Gene 285: 1-24, 2002.

12. Rawlings JS, Rosler KM and Harrison DA: The JAK/STAT signaling pathway. J Cell Sci 117: 1281-1283, 2004.

13. Manea SA, Manea A and Heltianu C: Inhibition of JAK/STAT signaling pathway prevents high-glucose-induced increase in endothelin-1 synthesis in human endothelial cells. Cell Tissue Res 340: 71-79, 2010.

14. Marrero MB, Banes-Berceli AK, Stern DM and Eaton DC: Role of the JAK/STAT signaling pathway in diabetic nephropathy. Am J Physiol Renal Physiol 290: F762-F768, 2006.

15. Godefroit P, Hai S, Yu T and Lauters P: New hadrosaurid dinosaurs from the uppermost Cretaceous of northeastern China. Acta Palaeontol Polonica 53: 47-74, 2008.

16. Tong Y and Hou H: Effects of Huangqi Guizhi Wuwu Tang on diabetic peripheral neuropathy. J Altern Complement Med 12: 506-509, 2006

17. Sun T, Cao L, Ping NN, Wu Y, Liu DZ and Cao YX: Formononetin upregulates nitric oxide synthase in arterial endothelium through estrogen receptors and MAPK pathways. J Pharm Pharmacol 68: 342-351, 2016.

18. Wu J,Ke X, Ma N, Wang W, Fu W, Zhang H,Zhao M, Gao X, Hao X and Zhang Z: Formononetin, an active compound of Astragalus membranaceus (Fisch) Bunge, inhibits hypoxia-induced retinal neovascularization via the HIF-1 $\alpha$ /VEGF signaling pathway. Drug Des Dev Ther 10: 3071-3081, 2016.

19. Wu JH, Li Q, Wu MY, Guo DJ, Chen HL, Chen SL, Seto SW, $\mathrm{Au}$ AL, Poon CC, Leung GP, et al: Formononetin, an isoflavone, relaxes rat isolated aorta through endothelium-dependent and endothelium-independent pathways. J Nutr Biochem 21: 613-620, 2010.

20. Livak KJ and Schmittgen TD: Analysis of relative gene expression data using real-time quantitative PCR and the 2(-Delta Delta C(T)) method. Methods 25: 402-408, 2001.

21. Cosentino F, Hishikawa K, Katusic ZS and Lüscher TF: High glucose increases nitric oxide synthase expression and superoxide anion generation in human aortic endothelial cells. Circulation 96: 25-28, 1997.

22. Dabelea D and Harrod CS: Role of developmental overnutrition in pediatric obesity and type 2 diabetes. Nutr Rev 71 (Suppl 1): S62-S67, 2013. 
23. Wiernsperger NF and Bouskela E: Microcirculation in insulin resistance and diabetes: More than just a complication. Diabet Metab 29: 6S77-6S87, 2003.

24. Ndisang JF, Rastogi S and Vannacci A: Insulin resistance, type 1 and type 2 diabetes, and related complications 2015. J Diabetes Metab 2015: 234135, 2015.

25. Palmer SC, Mavridis D, Nicolucci A, Johnson DW, Tonelli M, Craig JC, Maggo J, Gray V, De Berardis G, Ruospo M, et al: Comparison of clinical outcomes and adverse events associated with glucose-lowering drugs in patients with type 2 diabetes: A meta-analysis. JAMA 316: 313-324, 2016.

26. Jermendy G: Can type 2 diabetes mellitus be considered preventable? Diabetes Res Clin Pract 68 (Suppl 1): S73-S81, 2005.

27. Lee H, Lee D, Kang KS, Song JH and Choi YK: Inhibition of intracellular ROS accumulation by formononetin attenuates cisplatin-mediated apoptosis in LLC-PK1 cells. Int J Mol Sci 19, 2018.

28. Wang Y, Zhu Y, Gao L, Yin H, Xie Z, Wang D, Zhu Z and Han X: Formononetin attenuates IL-1 $\beta$-induced apoptosis and NF- $\kappa \mathrm{B}$ activation in INS-1 cells. Molecules 17: 10052-10064, 2012.

29. Qiu G, Tian W, Huan M, Chen J and Fu H: Formononetin exhibits anti-hyperglycemic activity in alloxan-induced type 1 diabetic mice. Exp Biol Med (Maywood) 242: 223-230, 2017.

30. Vargha R, Bender T, Riesenhuber A,Endemann M, Kratochwill K and Aufricht C: Effects of epithelial-to-mesenchymal transition on acute stress response in human peritoneal mesothelial cells. Nephrol Dial Transplant 23: 3494-3500, 2008.

31. Schindler C, Levy DE and Decker T: JAK-STAT signaling: From interferons to cytokines. J Biol Chem 282: 20059-20063, 2007.

32. Liao JQ, Lin JQ, Zhang WJ, Xu L, Zhi XM, Lin K and Wu W: Role of JAK/STAT signaling pathway in high glucose-induced damage in human umbilical vein endothelial cells. Chin J Pathophysiol 32: 392-397, 2016 (In Chinese).
33. Budihardjo I : Biochemical pathways of caspase activation during apoptosis. Annu Rev Cell Dev Biol 15(1):269-290,1999.

34. Griendling KK, Sorescu D and Ushio-Fukai M: NAD(P)H oxidase: Role in cardiovascular biology and disease. Circ Res 86: 494-501, 2000.

35. Mehta JL and Li D: Identification, regulation and function of a novel lectin-like oxidized low-density lipoprotein receptor. J Am Coll Cardiol 39: 1429-1435, 2002.

36. Dinarello CA: Biologic basis for interleukin-1 in disease. Blood 87: 2095-2147, 1996

37. Merhi-Soussi F, Kwak BR, Magne D, Chadjichristos C, Berti M, Pelli G, James RW, Mach F and Gabay C: Interleukin-1 plays a major role in vascular inflammation and atherosclerosis in male apolipoprotein E-knockout mice. Cardiovasc Res 66: 583-593, 2005.

38. Yang L, Froio RM, Sciuto TE, Dvorak AM, Alon R and Luscinskas FW: ICAM-1 regulates neutrophil adhesion and transcellular migration of TNF-alpha-activated vascular endothelium under flow. Blood 106: 584-592, 2005.

39. Clapp BR, Hingorani AD, Kharbanda RK, Mohamed-Ali V, Stephens JW, Vallance P and MacAllister RJ: Inflammationinduced endothelial dysfunction involves reduced nitric oxide bioavailability and increased oxidant stress. Cardiovasc Res 64: 172-178, 2004.

40. Förstermann U and Sessa WC: Nitric oxide synthases: Regulation and function. Eur Heart J 33: 829-837, 837a-837d, 2012.

41. Wang X, Shaw S, Amiri F, Eaton DC and Marrero MB: Inhibition of the JAK/STAT signaling pathway prevents the high glucose-induced increase in TGF-beta and fibronectin synthesis in mesangial cells. Diabetes 51: 3505-3509, 2002. 